\title{
Treatment Duration of Topics in Senior Secondary School Core Mathematics in Ghana: A Case Study of Cape Coast District
}

\author{
Asare-Inkoom, A. \\ Department of Science Education, University of Cape Coast \\ Cape Coast, Ghana \\ Gyening $\mathbf{J}$. \\ Department of Science Education, University of Cape Coast \\ Cape Coast, Ghana
}

\begin{abstract}
The purpose of the study was to investigate whether the intended time of 160 minutes per week for 96 weeks was adequate for the treatment of the SSS Core Mathematics. The study used simple random sampling method to select two mixed, two single-sex female and two single-sex male Senior Secondary Schools in the Cape Coast Education District of the Central Region of Ghana. The study involved 790 students. Three achievement tests in mathematics were used to collect data. The data were analyzed by means of student t-test. The results showed that the intended time of 160 minutes per week for 96 weeks for the SSS Core Mathematics Program was inadequate.
\end{abstract}

\section{Introduction}

A society's most valuable resource is its people and education is a process by which society invests in the development of its people (Pratt, 1980). Of the many resources committed to its investment, according to Pratt (1980), the most significant is time. Time is the one resource that is non-renewable, non-interchangeable and finite. By far the greatest amount of time that is used in schools is that spent by pupils, time that is committed not by their own consent but by order of their elders (Pratt, 1980).

Mathew (1989) shared the opinion that a pupil's level of attainment was directly related to the length of time actively spent on learning. Kraft (1994) also said that the amount of time spent on the basics of language and mathematics is a critical factor in the achievement level of students. Taylor and Richards (1985) gave two basic ways to allot time for the subjects in the curriculum. These two ways, they said were the allotment of time in unit lesson or period and the holistic time allotment. In allotment of time to the subjects, consideration should be given to the number of activities involved in the teaching and learning of the subjects. In other words, in allotting time to a particular subject, say mathematics, the topics to be treated within the syllabus were to be taken into account.

Many studies had revealed the high educational standards in mathematics in Japan (Greer and Mulhern, 1989). The first of these was the International Study of Achievement in mathematics carried out in the mid-1960s (Husen, 1967; Lynn, 1989). In this study, data were collected relating to achievement in mathematics of 13-year-olds and 18-year-olds from the United States, England, Australia and a number of nations in continental Europe (Lynn, 
1980). According to Lynn (1989) the Japanese obtained the highest means in all the samples. Among the factors discussed was time spent on mathematics. According to Lynn (1989), Stigler, Lee and Steven (1987) found that Japanese and Chinese children spent much more time on learning mathematics than American children. For example, in the first grade, the number of hours per week spent on mathematics were 2.9 (US), 3.9 (Taiwan) and 6.0 (Japan). Again at the fifth grade the corresponding figures were 3.4 (US), 11.4 (Taiwan) and 7.6 (Japan) - (Stigler, Lee and Stevenson, 1987; Lynn, 1989).

Kraft (1994) had said the amount of time spent on the basics of language and mathematics is a critical factor in the achievement level of students. Though Kraft's (1994) study was focused on the primary education, it gives insight into time allocation and time use in our schools. According to Kraft (1994) while the length of primary school year in Ghana was 800 hours per year, it was 1080 hours, 1290 hours and 1128 hours per year in Benin, Burkina Faso and Nigeria respectively

(Kraft, (1994: 77). In the USA and Japan, the figures were respectively 1080 and 1440 hours per year (Kraft, (1994: 77). Again according to Kraft (1994) seven periods of 30 minutes each $(210$ minutes $)$ were allotted for mathematics instructions at the primary level.

According to Anamuah-Mensah (1995), many research studies had demonstrated the effects of education on productivity. Citing UNESCO (1990), Anamuah-Mensah said that a recent study seemed to suggest an increase of one year in average years of education might lead to threepercent rise in Gross National Product (GNP), (Anamuah-Mensah, 1995; UNESCO, 1990). Mathews (1989) also said that research had confirmed that pupil's level of attainment was directly related to the length of time actively spent in learning. This was also confirmed by the International Assessment of Educational Progress (IAEP) project in 1991/92. According to the study, countries which scored above 70 percent on the achievement test were spending, on the average, more than 200 minutes (apart from Korea which was spending 179 minutes) on mathematics instructions a week (IAEP Report, (1992; 49). For example, China, which obtained the first position on the achievement test with a score of 80 percent, was spending an average weekly time of 307 minutes on mathematics (IAEP Report, (1992: 49).

The decision to change the general structure and content of education in Ghana dates as far back as $1973 / 74$. The need for the change resulted from the recognition that any educational system should aim at serving the needs of the individual, society in which he lives and the country as whole. The report of the Committee set up to advise on the implementation of Junior Secondary School (JSS) Program (1986) indicated after reviewing the old education structure that, the first cycle was plagued with multiplicity of parallel programs, namely:

a. continuation school program,

b. middle school program and

c. junior secondary program. 
Again some private schools were running a six-to-eight year course. The Committee observed that the parallel programs made it difficult to develop instructional materials and work out examination or evaluation procedures for these programs concurrently. The parallel programs also made it difficult to utilize scarce resources for the multiple programs. It was also realize that the existing structure of education was rather too long, and as such expensive. The content of education at both first and second cycles was devoid of practical skills that could equip students so that they could pursue different vocations. As remarked by Fafunwa (1967) and quoted by Bishop (1985):

The syllabi of most of the subjects taught are replicas of English, French or Portuguese syllabi. Under such conditions the students that Africa will produce will be those who are African in blood but English, French or Portuguese in opinion, morals and intellect. Consequently they will tend to be "misfits" in their society. Unquestionably, wholesale curriculum reconstruction is well overdue in Africa and we mean that a radical change both in content and orientation is needed. (Bishop, (1985:241).

The new structure and content of education for Ghana, therefore, seeks to diversify education and introduce practical skills as early as possible at both the JSS and Senior Secondary School (SSS) levels. The JSS program began with the establishment of some Junior Secondary Schools on experimental basis in 1976, following the acceptance of Dzobo Report of 1974. Due to lack of both funds and political will, the new program could not be fully implemented until 1987. Prior to this period, public debates and fora were organized to collate views from the general public on the new education reforms (Education Reform Review Committee Report, 1994). Some Ghanaians expressed mixed feelings about the innovation. While others had their own reservations about the success of the reforms, others felt that there would be lowering of standards in our schools. Others also felt that the implementation process should have been done gradually or in phases instead of complete take off throughout the country. Others still felt that the three-year duration was short, compared with the former seven-year secondary education.

One group that had shown much concern about the duration of the SSS program was the Conference of Heads of Assisted Secondary Schools (CHASS). CHASS called for the review of the SSS program and suggested a change in the duration of the course from three to four years (Sam, 1992; Eminah, 1993).

Delivering a paper on the topic: "The Senior Secondary - A Forward Look" at the 32nd Annual Conference of CHASS, Professor D. A. Acheampong suggested that the SSS should be a four-year program. Again, delivering a lecture on the topic: "Crisis in Education" during John Mensah Sarbah memorial lectures on the $11^{\text {th }}$ November 1997, Mr. K. B. Asante, a retired diplomat, suggested that the SSS program should be four years so that the products would benefit from university and other tertiary education (News Item of Radio Ghana at 6 a.m. on 12 th November 1997; Daily Graphic of November $15^{\text {th }}$ 1997). Recently University Teachers Association of Ghana (UTAG) also called for the extension of the SSS program from three to four 
years to better equip the students for university education (Daily Graphic of September $15^{\text {th }}$ 1998).

The release of the first result of the Senior Secondary School Certificate Examination (SSSCE) in 1993, sparked off adverse comments and criticisms from the public. The furor following the release of the results led to the formation of the Education Reform Review Committee (ERRC) in 1994 and was charged to look at the whole reform programme and make necessary recommendations for improvement. Among the recommendations the Committee made was that

There should be a 6-3-4-4 structure of education. The number of years for the SSS program should be increased from three to four years, effectively increasing the number of years for pre-tertiary education from 12 to 13 (ERRC Report, 1994:14).

In the opinion of the Committee, in consideration of the philosophical and sociological basis of the educational reforms, the structure 6-3-4-4 is most cost-effective despite the increase in budget and also most equitable (ERRC Report, (1994:13). However, the Ministry of Education did not agree with the recommendation of ERRC that the structure of education should be 6-3-4-4, by increasing the duration of the SSS program from three to four years (Ministry of Education, 1994: 2).

The suggestion for the increment in the number of years of the SSS program from three to four by CHASS, ERRC, UTAG and other individual Ghanaians, pre-supposes that perhaps, the times allotted for the treatment of the various subjects in the SSS syllabi, including Core Mathematics, were inadequate. Time allotment in secondary schools before the inception of the SSS program in 1990 was 240 minutes a week for mathematics instructions. One would have expected the instructional time for the core subjects to be increased following the reduction of the number of core subjects from six to four (The Ministry of Education's views on the report of ERRC, October 1994). The time still remains 160 minutes a week for core mathematics instructions.

There seemed, therefore, to be a controversy on the intended time for the SSS program. While a section of Ghanaian community (example CHASS, ERRC, UTAG, etc.) felt that the intended time be increased, The Ministry of Education (and for that matter the government) insisted that it should remain the same. So far, there had not been any study to address this problem to empirically find out whether the intended time of 160 minutes per week for 96 weeks was adequate for the SSS Core Mathematics Program, apart from what Kwetey (1996) conducted in the Keta and Ketu Districts in the southern sector of the Volta Region of Ghana.

It appears research shows that there is an international consensus that school days and school years need to be lengthened in many countries in the world (Kraft, 1994). According to Kraft (1994), not only do Ghanaian children spend less time in school than many others, but that the actual 'academic learning time' is even less - in the area of two to three hours a day (Kraft, (1994: 17). A visit to some of the schools in the municipality by the researcher revealed that time allotted for mathematics instruction ranges between eight and ten periods of 30 minutes each (240 to 300 minutes) a 
week in the Primary Schools, while at the JSS level the corresponding time allocation is between five and six periods of 35 minutes each (175 to 210 minutes) a week.

This study was, therefore, designed to investigate whether the intended average duration of 404 minutes per topic was adequate for the SSS Core Mathematics Programme.

\section{Methodology}

\section{Population and Sample}

The population was made up of all the students in the ten government assisted SS schools in the Cape Coast Education District. The sample was made up of all students in the three selected classes (one in SS1, one in SS2 and one in SS3) in each of the six randomly selected schools. These students were made up of 358 girls and 432 boys (790 in all), and were pursuing the General Arts Program who were moderate achievers in mathematics. The students had their ages ranging between 14 and 19 years.

\section{Instrument}

The instruments used were three achievement tests; one for SS1, one for SS2 and the other for SS3. Students were assumed to have understood the selected topics if two-thirds of each group obtained a minimum score of 40 percent in the achievement tests administered after the treatment (Bloom, (1971: 47); Pratt, (1985: 219).

The SS1 achievement test was made up of 10 items on all the sub-topics of the topic 'Algebraic Expressions'. The items were similar to the questions in the SS Mathematics Book 1, and it was made up of 60-minute written (essay) items. Each item carried six marks. Thus the maximum mark that could be obtained by a student was 60 and the least score was zero. For example item 5 on the SS1 achievement test reads:

$$
\text { Multiply } \frac{2 a}{(a-b)^{2}} \text { by } \frac{a-b}{a+b} \text {. }
$$

The SS2 achievement test was made up of five items covering all the subtopics of the topic 'Statistics'. The items were similar to what were in the SS Mathematics Book 2, and it was a 60 minutes written (essay) paper. Each item carried 12 marks and items were based on the Year Two Statistics of the SS Mathematics Program. Thus a maximum of 60 marks could be obtained by a student, and the least score was zero. For example item e on the SS2 achievement test reads:

The ages, in years, of ten men are

$\begin{array}{llllllllll}42 & 28 & 40 & 33 & 31 & 32 & 52 & 45 & 37 & 40 .\end{array}$

Calculate the standard deviation of the distribution.

The SS3 achievement test was also made up of five items similar to those in the SS Mathematics Book 3, and covered all the sub-topics of the topic 'Applications of Trigonometry'. For example item 2 on the SS3 achievement 
test reads: 'A tree casts a shadow 9 meters long when the angle of elevation of the sun is $23^{\circ}$. How tall is the tree?'

\section{Reliability}

The achievement tests were pilot tested on the 100 girls from the two female schools involved in the study. These 100 girls were made up of 40 SS3 girls from one of the schools and 31 SS2 and 29 SS1 girls from the other school in the 1995/96 academic year who had been taught the selected topics. The two female schools are in the Cape Coast Education District and the 100 girls on whom the achievement tests were pilot tested were not involved in the main study. At the time of the pilot study, the SS3 girls from one of the schools were writing their mock examinations and this accounted for the inclusion of the 40 girls from the other school. Students' scripts were scored and the reliability coefficients were calculated using the Cronbach (1951) alpha formula. The reliability coefficients were found to be $0.84,0.74$ and 0.75 for the SS3, SS2 and SS1 achievement tests respectively.

\section{Procedure}

To find out how much time was needed for the treatment of the selected topics, the researcher conducted an experimental teaching in one class in SS1, one class in SS2 and one class in SS3 (all classes were pursuing the General Arts Program) of one of the females schools. This school was chosen for the experimental teaching because of the school's willingness to accept the researcher who was a former staff member. The classes were purposively selected after consultations with the Head of Mathematics Department of the school, who was also the Assistant Headmistress (Academic) for the school. Lesson notes on the selected topics were prepared and taught to students.

For the SS1 selected class, the experimental teaching was conducted daily between $27^{\text {th }}$ February and 12th March 1997, all between 9.40 am and 11.00 am - treatment duration of 80 minutes daily for the period.

The experimental teaching for the SS2 class was conducted weekly in the afternoon between 4.00 and 5.20 from February 25th and March $10^{\text {th }} 1997$. Two more experimental teachings were conducted on April 29th and May $16^{\text {th }}$ 1997(in the Second Term) all between 4.00 and 5.20 in the afternoon.

Four experimental lessons were conducted in the SS3 selected class, all in the afternoon, between 26th of February and 24th April, 1997. After two lessons, the whole exercise had to be postponed to second term because of the Schools and Colleges Sports Festival. The four experimental teachings were held on two consecutive days each week, - i.e. on $26^{\text {th }}$ and $27^{\text {th }}$ of February and again on 23rd and 24th April 1997, - all between 2.00 and 5.20 in the afternoon.

In consultation with the Heads of Mathematics Departments in the other selected schools, other experienced teachers were purposively selected to conduct similar experimental teachings in their respective schools. There were 15 teachers in all, made up of 10 graduates, two 'diplomates' and three specialists. These teachers had between six and twenty-six teaching experience. Records of instructional activities on the selected topics were photocopied and made available to the teachers. These instructional 
activities were explained to the teachers to follow in order to ensure uniformity in all the selected schools. Teachers were asked to keep records of actual time spent on treating the selected topics in their respective classes. The researcher personally conducted the achievement tests in the selected schools after the experimental teaching by the teachers.

In order to cover more topics in the SSS Mathematics Syllabus, apart from the selected ones, the selected teachers were asked to keep records of the number of topics treated and the time spent on each treated topic for the term - second term of 1996/97 academic year.

\section{Hypotheses}

The following null hypotheses were formulated and tested, all at five percent significant level, as regards the problem at stake.

1. The actual mean time used in teaching the selected topics is not significantly higher than the average intended time allotted for the treatment of the SSS Core Mathematics.

2. There is no significant difference between the actual mean time used in teaching Algebraic Expressions and the average intended time allotted for treating the SS1 Core Mathematics.

3. There is no significant difference between the actual mean time used in teaching Statistics and the average intended time allotted for treating the SS2 Core Mathematics.

4. There is no significant difference between the actual mean time used in teaching Applications of Trigonometry and the average intended time allotted for treating the SS3 Core Mathematics.

\section{Results}

Table 1 below shows the actual times used by the researcher and the other teachers in teaching the selected topics.

Table 1 Times (minutes) spent in treating the selected topics.

\begin{tabular}{cccc}
\hline School & \multicolumn{3}{c}{ Time (minutes) spent } \\
\hline & SS1 & SS2 & SS3 \\
A & 720 & 400 & 320 \\
B & 520 & 480 & 400 \\
C & 1160 & 280 & 480 \\
D & 400 & 400 & 320 \\
E & 720 & 640 & 640 \\
F & 450 & 600 & 320 \\
\hline
\end{tabular}

Table 2 shows the number of topics treated and the actual times spent by the teachers for second term in the 1996/97 academic year in the selected schools. 
Table 2 Number of topics treated and the average times (minutes) spent for second term by teachers in the schools

\begin{tabular}{lccc}
\hline School & Class & \multicolumn{1}{c}{$\begin{array}{c}\text { Number } \\
\text { of Topics }\end{array}$} & $\begin{array}{l}\text { Average } \\
\text { Time }\end{array}$ \\
\hline A. Wesley Girls' & SS1 & 8 & 513 \\
High School & SS2 & 4 & 576 \\
B. Holy Child & SS3 & 5 & 352 \\
School & SS1 & 5 & 528 \\
& SS2 & 7 & 274 \\
C. Mfantsipim & SS3 & 5 & 352 \\
School & SS1 & 7 & 617 \\
& SS2 & 4 & 450 \\
D. St. Augustine's & SS3 & 4 & 360 \\
College & SS1 & 7 & 429 \\
& SS2 & 7 & 329 \\
E. Aggrey & SS3 & 5 & 480 \\
Memorial & SS1 & 4 & 500 \\
School & SS2 & 6 & 433 \\
F. Ghana National & SS3 & 4 & 600 \\
College & SS1 & 6 & 480 \\
& SS2 & 5 & 528 \\
\hline
\end{tabular}

The computation of the Average Intended Times for the various forms were calculated with the formula $\frac{C W}{T C} \times T$

Where CW is Total Number of Contact Weeks; TC is Total Number of Topics Covered; $\mathrm{T}$ is the number of minutes used for the treatment of Mathematics per week.

The results obtained when the Average Intended Times for the various forms were calculated is presented in Table 3.

Table 3 Average Intended Times calculated for each class

\begin{tabular}{lc}
\hline Form & $\begin{array}{l}\text { Minutes used for the treatment } \\
\text { of Mathematics per week. }\end{array}$ \\
\hline SS1 & 320 \\
SS2 & 389 \\
SS3 & 600 \\
All & 404 \\
\hline
\end{tabular}

Tables 4 and 5 show the descriptive statistics of the time spent in teaching the selected topics and descriptive statistics of the time spent by the 
teachers in the second term of 1996/97 academic year respectively. Tables 6 and 7 show the computation of t- statistic for the testing of the Hypotheses.

Table $4 \quad$ Actual Mean Times and Standard Deviation

\begin{tabular}{|c|c|c|c|c|c|c|c|c|c|c|}
\hline CLASS & $\mathrm{N}$ & MEAN & MEDIAN & TRMEAN & STDEV & SEMEAN & MIN & MAX & $\mathrm{Q}_{1}$ & $\mathrm{Q}_{2}$ \\
\hline SS1 & 6 & 662.0 & 620 & 662.0 & 279.0 & 114.0 & 400 & 1160 & 438 & 830 \\
\hline SS2 & 6 & 446.7 & 440 & 466.7 & 135.4 & 55.3 & 280 & 640 & 370 & 610 \\
\hline \multirow[t]{2}{*}{ SS3 } & 6 & 413.3 & 360 & 413.3 & 128.2 & 52.3 & 320 & 640 & 320 & 520 \\
\hline & 18 & 513.9 & 465 & 488.1 & 212.5 & 50.1 & 280 & 1160 & 380 & \\
\hline
\end{tabular}

Table $5 \quad$ Mean Times and standard deviations for second term

\begin{tabular}{lrrrrrrrrrl}
\hline CLASS & N & MEAN & MEDIAN & TRMEAN & STDEV & SEMEAN & MIN & MAX & Q1 & Q2 \\
\hline SS1 & 6 & 511.2 & 506.5 & 511.2 & 62.2 & 25.4 & 429 & 617 & 457.3 & 550.3 \\
SS2 & 6 & 431.7 & 441.5 & 431.7 & 114.8 & 46.9 & 274 & 576 & 315.3 & 540.0 \\
SS3 & 6 & 432.3 & 405.0 & 432.3 & 98.8 & 40.3 & 352 & 600 & 352.0 & 510.0 \\
& 18 & 458.4 & 465.0 & 460.0 & 96.7 & 22.8 & 274 & 617 & 358.0 & 528.0 \\
\hline
\end{tabular}

Table $6 \quad$ T-statistic for difference between Actual Mean Times with the Average Intended Times for first term

\begin{tabular}{cclcccl}
\hline & $\mathrm{N}$ & MEAN & STDEV & SEMEAN & \multicolumn{1}{c}{ T } & P-VALUE \\
\hline SS1 & 6 & 661.667 & 278.741 & 113.796 & $3.00^{*}$ & $0.030^{*}$ \\
SS2 & 6 & 466.667 & 135.450 & 55.297 & 1.40 & 0.22 \\
SS3 & 6 & 413.333 & 128.167 & 52.324 & $-3.57^{*}$ & $0.016^{*}$ \\
OVERALL & 18 & 513.88 & 212.468 & 50.079 & $2.19^{*}$ & $0.021^{*}$ \\
\hline
\end{tabular}

* Significant at $\mathrm{p}<0.05$

Table $7 \quad$ T-statistic for difference between Actual Mean Times with the Average Intended Times for second term

\begin{tabular}{ccccccc}
\hline & $\mathrm{N}$ & MEAN & STDEV & SEMEAN & T & P-VALUE \\
\hline SS1 & 6 & 511.167 & 62.185 & 25.387 & $7.53^{*}$ & $0.0007^{*}$ \\
SS2 & 6 & 431.667 & 114.760 & 46.851 & 0.91 & 0.40 \\
SS3 & 6 & 432.333 & 98.828 & 40.347 & $-4.16^{*}$ & $0.0089^{*}$ \\
OVERALL & 18 & 458.389 & 96.738 & 22.801 & $2.39^{*}$ & $0.014^{*}$ \\
\hline \multicolumn{5}{c}{ * Significant at $\mathrm{p}<0.05$}
\end{tabular}




\section{Discussion}

On the experimental teaching, actual mean time for the treatment of Algebraic Expressions in Year One was 662 minutes (about four weeks). That for Statistics in Year Two was 467 minutes (about three weeks). In Year Three, the actual mean time for the treatment of Applications of Trigonometry was 413 minutes (about three weeks). These figures were arrived at after considering all the actual times spent by the teachers who helped in the experimental teaching. It is interesting to note that in one of the SS3 classes, the teacher spent 320 minutes (two weeks) in treating the selected topic. After the conduct of the achievement test, only 23 percent of the students passed with a minimum mark of 40 percent. A further 160 minutes (one week) treatment of the topic in the class resulted in 70 percent pass, given the treatment time for the topic in the class to be 480 minutes (three weeks). In another class of another selected school, the treatment time of 480 minutes (three weeks) by another teacher resulted in 13 percent pass on the achievement test. A further 160 minutes (one week) treatment of the topic in the class by the teacher resulted in 68 percent pass in the achievement test.

These revelations appear to support Mathews' opinion that 'a pupil's level of attainment was directly related to the length of time actively spent on learning' (Mathew, 1989). This had also been confirmed by many research studies, examples of which were Stigler, Lee and Stevenson (1987) study in Japan, China and the USA; Lynn (1989) report of the study of achievement in Mathematics and Science among 12-year-olds commissioned by the Dallas Times Herald in 1983; and the international Assessment of Educational Progress Project carried out in 20 countries worldwide in 1990/91 (IAEP Report, 1992).

Data collected on the mathematics topics treated and the time spent on the topics by 18 teachers for the Second Term of 1996/97 Academic Year indicated that for the term;

- six topics, on the average, were treated in Year One,

- the average treatment time for Year One was 511 minutes ( $3 \frac{1}{5}$ weeks) per topic,

- $\quad$ six topics were averagely treated in Year Two,

- the average treatment time for Year Two was 432 minutes (about three weeks) per topic,

- on the average, five topics were treated in Year Three,

- the average treatment time for Year Three was 432 minutes (about three weeks) per topic,

- the overall average number of topics treated by the 18 teachers in the term as five,

- the overall average treatment time for the term was 458 minutes (about three weeks) per topic (see Table 2).

On the hypotheses, it was found that the actual mean time (514 minutes) for treating the SSS Core Mathematics was significantly higher than the average 
intended time (404 minutes). This hypothesis was tested, using the student's t-statistic, at five percent level of significance [see Table 6). Again, there was significant difference between the actual mean time (662 minutes) and the average intended time $(320$ minutes) for treating the SS1 Core Mathematics. This hypothesis was consistent with Kwetey's (1996) study where the actual mean time was found to be more than the average intended time.

However, there was no significant difference between the actual mean time (467 minutes) and the average intended time (389 minutes) for treating the SS2 Core Mathematics. It was found that there was significant difference between the actual mean time (413 minutes) and the average intended time (600 minutes) for treating the SS3 Core Mathematics. In brief, while the null hypotheses 1,2 and 4 were all rejected, hypothesis 3 was accepted, all at five percent level of significance.

Using the student's t-statistic to compare the average intended times with the actual mean times used by the 18 teachers in treating core mathematics topics for the Second Term of the 1996/97 Academic Year, it was found that the actual mean time for the term (458 minutes) was significantly higher than the average intended time (404 minutes). This test was done using five percent level of significance and $t^{*}$ was 2.39 ( $>1.740$ - $t$ value from Tables) while P-Value was $0.014(<0.05)$. In SS1, the term's mean treatment time (511 minutes) was also significantly different from the average intended time (320 minutes). The $\mathrm{t}^{*}$ value was $7.53(>2.571-\mathrm{t}$ value from Tables) and $\mathrm{p}$ value was also $0.0007(<0.05)$. In SS3, the $\left|\mathrm{t}^{*}\right|$ value was $4.16(>2.571)$ while p-value was also $0.0089(<0.05)$. This shows that the term's actual mean treatment time (432 minutes) for SS3 Core Mathematics was significantly different from its corresponding average intended time (600 minutes).

For the term, again it was in SS2 that there was no significant difference between the term's actual mean treatment time (432 minutes) and its corresponding average intended time (389 minutes). This time, the $t^{*}$ value was $0.91(<2.571)$ and p-value was also $0.40(>0.05)$ [see Table 7].

It was interesting to note that the actual mean times for treating the selected topics in the various forms were all significantly different from their corresponding average intended times except in SS2. This, in part, implied full utilization of teacher-student contact hours was not realized in SS1 and SS3.

In SS1, students report to school in the first term long after re-opening. For example in 1996/97 Academic Year, when the data collection was carried out, SS1 students reported to school, in the first term, in the fourth week of re-opening of schools. These students further underwent orientation exercises before starting academic work. In some of the selected schools, before the students settled for any meaningful academic to begin, the term was almost ended. Thus in such schools no meaningful utilization of teacher-student contact hours was achieved in the first term. Besides this late arrival of these students, it is in Year One that a lot of mathematics 
topics are supposed to be treated - 16 topics as compared to 14 in SS2 and 8 in SS3 SSS Core Mathematics Syllabus).

In SS3, again students complete their final examinations (SSSCE) before the end of the end of the academic year. This also denies the students the benefits of the full teacher-student contact hours. One needs to mention also series of activities like inter-schools sports and others that take students off the classroom. The research, therefore, welcomes the Ministry of Education's decision to change the Academic Calendar for Senior Secondary Schools from December-January to August-September (Daily Graphic, November 10th 1997 , p.1 col.3-4).

It should also be noted that all the schools involved in the study were Grade A as well as urban. One can, therefore, envisage the situation in other schools, especially in the rural SS schools.

\section{Comparison of the Situation in Ghana with that of other Countries}

Table 8 shows the disparities in the average days of instructions, average minutes of instructions and average minutes of mathematics instruction in Ghana and other countries.

Table $8 \quad$ Disparities in Treatment Duration of Mathematics in some Countries.

\begin{tabular}{|l|c|c|c|}
\hline \multicolumn{1}{|c|}{ Country } & $\begin{array}{c}\text { Average Days of } \\
\text { Instruction in Year }\end{array}$ & $\begin{array}{c}\text { Average Minutes of } \\
\text { Instruction Each Day }\end{array}$ & $\begin{array}{c}\text { Average Minutes of } \\
\text { Mathematics Instruction in } \\
\text { School Each Week }\end{array}$ \\
\hline Brazil & 181 & 271 & 205 \\
Canada & 188 & 304 & 225 \\
China & 251 & 305 & 307 \\
England & 192 & 380 & 190 \\
France & 174 & 370 & 230 \\
Ghana ${ }^{*}$ & 200 & 320 & 160 \\
Israel & 215 & 278 & 205 \\
Mozambique & 193 & 272 & 217 \\
Soviet Union & 198 & 243 & 258 \\
United States & 178 & 338 & 228 \\
\hline
\end{tabular}

Source:

The International Assessment of Educational Progress Report, 1992 (Ghana excluded)

It is evidently clear from Table 7 above that, of all the countries, it was Ghana that had the least amount of instructional time (160 minutes per week) for mathematics. Mozambique, an African country like Ghana, even had 217 minutes for mathematics instruction per week, though she obtained the least position on the achievement test with a score of 28 percent (IAEP Report, (1992: 49).

The disparity becomes even more glaring when compared with the situations in some of the advanced countries like Canada and the United States. While Ghana's time was 160 minutes per week, Canada and the United States had respectively 225 minutes and 228 minutes per week for mathematics 
instructions. China, which obtained the first position on the achievement test with a score of 80 percent, was allotting 307 minutes per week for mathematics instructions (IAEP Report, (1992: 49).

A look at the table again depicts that while Ghana allots an average time of 1600 minutes per week (320 minutes per day) for teaching instructions, only 160 minutes (only 10 percent) is allotted to the teaching of mathematics. This could be compared with the situation in Mozambique, an African country involved in the IAEP Study, where out of an average time of 1360 minutes per week (272 minutes per day) allotted to teaching, 217 minutes (16 percent) was for teaching of mathematics (IAEP Report, 1992).

This inadequacy of treatment time for mathematics had compelled all the schools to adopt new teaching timetables in order to have more treatment time for the subjects taught in the schools. While some of the schools still maintain 160 minutes, others allot 200 minutes. Furthermore, while others allot 210 minutes some devote 240 minutes per week for the treatment of mathematics.

The teaching and learning of mathematics depend greatly on the teacher's competence in the subject. It is obvious that mathematics teachers should be abreast with current trends in mathematics teaching and learning. Mathematics classes should be made more interesting, practical and relevant to everyday activities. The Ghana Education Service (GES), as a matter of urgency should see to the organization of periodic in-service training for mathematics teachers in the short run. In the long run, training of more mathematics teachers should be emphasized as the study showed that some of the teachers teaching mathematics in the selected schools were not major-trained mathematics teachers. For example in one of the selected schools it was found that a teacher who majored in Visual Art was teaching both Visual Art and Mathematics.

The GES should again see to the writing of relevant mathematics textbooks, which are urgently needed in the schools. Agencies as well as individuals should be encouraged in this direction. This is a challenge to the Mathematical Association of Ghana (MAG) as well as the Curriculum Research and Development Division (CRDD) of the GES.

GES should come out with a unified number of periods for the various subjects in the SS curricula including mathematics. This might help to put a stop to the present situation where schools had allotted different time periods for mathematics instructions on the schools' timetables. For instance, while some schools had allotted six periods of 40 minutes a week, others had allotted five periods of 40 minutes a week. Others are still using four periods of 40 minutes a week, and still others are using different time periods for different forms in the same school. The researcher suggests six (6) periods of 40 minutes a week (240 minutes a week) for the treatment of Mathematics (Core) at the SSS level.

Results from the hypotheses indicated that, in SS1, the actual mean time was more than the average intended time for treating the SS1 Core Mathematics. Again in SS3, the actual mean time was less than the average intended time for the treatment of the SS3 Core Mathematics. This means 
that while the SS1 students have less time to do more work, the SS3 students have more work to do relatively less work in Core Mathematics. The researcher, therefore, suggests that some topics in SS1 could be delayed till SS2 and some topics in SS2 could be delayed till SS3 so that there may be fair distribution of the topics in the SS Core Mathematics in the three levels instead of the current 16, 14 and 8 topics in the respective levels.

According to Kraft (1994), research from other countries indicates that onefourth $(1 / 4)$ of the time in school is actual 'academic learning time'. In Ghana, research indicates that, due to tardiness, student and teacher absence, lack of instructional materials and a range of interruptions, the actual time given to English and Mathematics is even more severely limited (Kraft, (1994: 18). Kraft (1994), goes on to suggest that teachers need to be taught a host of strategies to make better use of time allotted to schooling. School Heads need to supervise classroom time use, not to talk about absenteeism of teachers and students. In addition, cutting down on interruptions (holidays), starting school on time, not ending early, and not having long breaks would all add to instructional time (Kraft, (1994: 78).

\section{References}

Abbiw, M. K. et al (1991). Ghana Senior Secondary School Mathematics Books 1, 2 \& 3 Oxford: International Education Unit of Oxford University Press.

Ablekpe, B. (1997). 'Academic Calendar to Change for SSS', Daily Graphic, 10 November, 1997, Front Page.

Acheampong, D. A. (1994). "The Senior Secondary - A Forward Look". A paper delivered at the32nd Annual Conference of Heads of Assisted Secondary Schools (CHASS) at Archbishop Porter Girls Secondary School, Takoradi.

Adjei, A. N. (1997). “The Mensah Sarbah Lectures their significance”. Daily Graphic, 15 November, 1997, p. 9.

Anamuah-Mensah, J. (1995). “The race Against Underdevelopment: A Mirage or Reality, The Journal of Science and Mathematics Education. Vol. 1 No. 1 p. 1

CHASS, (1994), Minutes of the First National Executive Meeting held at Accra Girls' Secondary School, Accra.

GHANA ,Ministry of Education, (1986). Report of the Committee set up to advise on the Implementation of Junior Secondary School Program. Accra: State Publishing Corporation.

GHANA, Ministry of Education, (1974). The New Structure and Content of Education for Ghana. Accra: State Publishing Corporation.

GHANA, Ministry of Education, (1994). Report of the Education Reform Review Committee. Accra: State Publishing Corporation.

GHANA, Ministry of Education, (1994). The Ministry of Education's Views on The Report of The Education Reform Review Committee (ERRC). Accra. 
GHANA, Ministry of Education, (Undated). Guidelines For The Implementation of Improved School Education Reforms Program. Accra.

Greer, B. and Mulhern, G. (1989). New Directions in Mathematics Education. Wiltshire: Anthony Rowe Ltd., Chippenham.

Harnisch, D. L. et al (1985). 'Mathematics productivity in Japan and Illinois' Evaluation in Education, An International Review Series 9; 277 - 84.

Hovarth, P. J. (1987). 'A Look at The Second International Mathematics Study Results In the USA and Japan', Mathematics Teacher 80: 359 68.

Husen, T. (1967). International Study of Achievement in Mathematics: A Comparison of Twelve Countries. Stockholm: Almquist and Wiksel.

IAEP, (1992). Educational Testing Service. Learning Mathematics: The International Assessment of Educational Progress. New Jersey: USA.

Kodzo-Akyire, N. (1998). "Is there a crisis in Education?" Daily Graphic, 15 November p.9 Col. $1-5$.

Kofoya-Tetteh, A. (1998). "Extend SSS Program to Four Years - UTAG". Daily Graphic, 15 September p. 1.

Kraft, R. (1994). Teaching and Learning in Ghana; A Curriculum, Textbooks, Syllabus and Handbook Analysis. A Report submitted to the Agency for International Development USAID mission in Accra, Ghana.

Kwetey, A. A. D. (1996). Treatment Duration of Some selected Topics in The Senior Secondary School Core Mathematics Syllabus. A Long Essay presented The Department of Science Education, Faculty of Education, University of Cape Coast, Cape Coast.

Lynn, R. (1989). 'Mathematics Teaching in Japan' in Brian Greer and Gerry Mulhern (ed.) New Directions in Mathematics Education, (1989), Wiltshire: Anthony Rowe Ltd. Chippenham.

Mathew's, J. (1989). Curriculum Exposed, London: David Fulton Publishers Ltd.

Mort, P. R. (1964). 'Studies in Educational Innovation' in M. B. Miles (ed.) Innovation in Education, Columbia: Teachers' College, New York.

Oldham, E. (1989). 'Is there an International Mathematics Curriculum?' in Brian Greer and Gerry Mulhern (ed.) New Directions in Mathematics Education, (1989), Wiltshire: Anthony Rowe Ltd. Chippenham, Great Britain.

Oliver, A. (1965). Curriculum Improvement; A Guide to Problems, Principles and Procedures, New York: Dodd Mead and Company Inc.

Pratt, D. (1980). Curriculum Design and Development, New York: Harcourt Brace Jovanouich Publishers

Spiegel, M. R. (1992). Schaum's Outline of Theory and Problems of Statistics. (2nd Edition) McGraw-Hill International, United Kingdom. 
Stigler, J. W. Lee, S. Y. and Stevenson, H. W. (1987). 'Mathematics Classrooms in Japan, Taiwan and the United States',. Child Development 58: $1272-85$.

UNESCO, (1975). The Experimental World Literacy Program; A Critical Assessment, Paris: France.

UNESCO, (1990). World Conference on Education For All; World Declaration on Education for All and Framework for Action to meet Basic Learning Needs, Paris: France. 